\title{
EDUCAÇÃO CONTINUADA EM UM SERVIÇO TERCEIRIZADO DE LIMPEZA DE UM HOSPITAL UNIVERSITÁRIO
}

\author{
Maria Inês Monteiro \\ Manuela de Santana Pi Chillida ${ }^{3}$ \\ Eliete Boaventura Bargas ${ }^{4}$
}

Monteiro MI, Chillida MSP, Bargas EB. Educação continuada em um serviço terceirizado de limpeza de um hospital universitário. Rev Latino-am Enfermagem 2004 maio-junho; 12(3):541-8.

A educação continuada tem sido tema de constantes reflexões devido à rápida evolução tecnológica, que traz modificações na organização do trabalho, exigindo dos trabalhadores atualização de seus conhecimentos. No contexto desse novo paradigma tecnológico nas relações de produção e na organização do trabalho, foram analisadas as atividades de educação continuada desenvolvidas junto aos trabalhadores terceirizados que atuam no setor de limpeza de um hospital universitário e foi avaliado seu conhecimento em relação ao risco de contaminação do ambiente de trabalho e a importância de seu trabalho para a manutenção de sua saúde. Foram realizadas seis entrevistas semi-estruturadas junto a trabalhadores terceirizados do setor de Limpeza e duas com os responsáveis pela educação continuada desses trabalhadores, além de quatro períodos de observação das atividades desenvolvidas e o diário de campo. Todos os trabalhadores consideraram essencial a educação continuada, pois não tinham experiência prévia sobre a limpeza no trabalho hospitalar.

DESCRITORES: educação continuada; serviço de limpeza; saúde ocupacional; serviços terceirizados; enfermagem

\section{PERMANENT EDUCATION IN AN OUTSOURCED CLEANING SERVICE AT A UNIVERSITY HOSPITAL}

Permanent education has been a source of constant reflections due to a rapid technological evolution, which brings about changes in work organization, and requires updated knowledge from workers. In the context of this new technological paradigm in production relations and work organization, we analyzed the permanent education activities involving outsourced workers in the cleaning sector of a university hospital and evaluated their knowledge about work environment contamination risks and the importance of their work for health maintenance. Six semi-structured interviews were carried out with the outsourced workers in the cleaning sector and two with the persons in charge of permanent education for these workers, besides four activity observation periods and the field diary. All workers considered permanent education essential because they had no previous experience in relation to hospital cleaning.

DESCRIPTORS: permanent education; cleaning; occupational health; outsourced services; nursing

\section{EDUCACIÓN CONTÍNUA EN UN SERVÍCIO DE LIMPIEZA POR TERCEROS} DE UN HOSPITAL UNIVERSITARIO

La educación continua ha sido tema de constantes reflexiones debido a la rápida evolución tecnológica, que ocasiona modificaciones en la organización del trabajo, exigiendo de los trabajadores actualización de sus conocimientos. En el contexto de este nuevo paradigma tecnológico en las relaciones de producción y en la organización del trabajo fueron analizadas las actividades de educación continua realizadas junto a los trabajadores tercerizados que actúan en el departamento de limpieza de un hospital universitario, además de evaluar su conocimiento con relación al riesgo de contaminación del ambiente de trabajo y la importancia de su trabajo para la manutención de su salud. Fueron realizadas seis entrevistas semi-estructuradas junto a trabajadores tercerizados del departamento de limpieza y dos con los responsables por la educación continua de estos trabajadores, cuatro períodos de observación de las actividades desarrolladas y el diario de campo. Todos los trabajadores entrevistados consideran la educación continua esencial, pues no tenían experiencia previa sobre la limpieza en el trabajo hospitalario.

DESCRIPTORES: educación continua; servicio de limpieza; salud ocupacional; servicios externos; enfermería

\footnotetext{
$\overline{1}$ Projeto financiado pelo PIBIC/CNPq - bolsa pesquisa; ${ }^{2}$ Professor Associado, Doutor em Enfermagem, Orientador da pesquisa, e-mail: inesmon@fcm.unicamp.br; ${ }^{3}$ Enfermeira, Mestre em Enfermagem; ${ }^{4}$ Acadêmica do $4^{\circ}$ ano do Curso de Graduação em Enfermagem. Faculdade de Ciências Médicas da Universidade Estadual de Campinas
} 
Estudos relativos à área Saúde e Trabalho e,

Com a internacionalização econômica e financeira e a instantaneidade da comunicação, surgem novas regras de produção e de organização do trabalho. O mundo do trabalho vem passando por profundas transformações. O elevado índice de desemprego vem acompanhado de um conjunto ampliado de insegurança, relativa ao emprego/desemprego, à contratação e à representação sindical. A precarização das condições de trabalho é um fenômeno marcante do final do século XX e início do XXI.

"A terceirização tem sido mais uma tática de redução de custos pela exploração de precárias relações de trabalho do que uma redução de custos baseada no aumento da eficiência e produtividade. A terceirização predatória está se tornando um mecanismo de flexibilização de direitos trabalhistas e sociais, em tempos de fragilidade do Estado, da sociedade organizada e dos sindicatos, em vez de flexibilizar a gestão da produção em tempos de instabilidade da demanda. [...] [Ela] tornouse uma forma de neutralizar a regularização estatal e a ação sindical e está acompanhada de sérias e negativas repercussões sobre a saúde dos trabalhadores"(1).

Deve ser destacado, no tocante à organização coletiva no Brasil, que os "setores mais modernos enfrentam uma ação sindical efetiva cuja eficácia os obriga ao encaminhamento de novas formas de gestão por meio da negociação. Na maioria dos outros setores, no entanto, a situação atual aponta para um processo gradativo de precarização do trabalho e fragilização da organização coletiva dos trabalhadores. O movimento sindical passa pelas dificuldades de lidar com uma situação fabril ao qual as políticas e estratégias de ação sindical parecem impotentes para deter a destruição de direitos e se relacionar com uma força de trabalho de características diversas daquelas encontradas no pátio das grandes empresas"(2).

A utilização extensiva da terceirização/ subcontratação conduz a um agravamento das condições de trabalho e a um aumento do grau de informalidade do mercado de trabalho. Em nome da produtividade e da competitividade atribuem-se a firmas "terceiras" tarefas anteriormente realizadas pelas empresas principais. No entanto, diante de um mercado de trabalho pouco qualificado e com grande disponibilidade de mão-de-obra, a economia de custos tem efeitos devastadores sobre a oferta de empregos. especificamente, de Saúde do Trabalhador são fundamentais para dar visibilidade aos problemas que perpassam as atividades laborais ${ }^{(3)}$.

Durante a realização da pesquisa de iniciação científica "Gênero \& Reestruturação produtiva; terceirização e impactos sobre a saúde"(4) que teve como objetivo traçar o perfil dos trabalhadores terceirizados que atuam no setor de serviços gerais de um hospital universitário, foi encontrada pequena qualificação profissional e escolaridade, uma vez que $8 \%$ da população estudada não freqüentou a escola, $64 \%$ possuíam escolaridade entre a primeira e a sétima série do ensino fundamental; além de o grupo ser composto basicamente por mulheres.

Face a tais fatores é importante refletir sobre esses trabalhadores, tendo em vista a sua atuação na área hospitalar.

As rápidas mudanças provocadas pelo avanço tecnológico, o progressivo processo de conscientização da população, aliada aos fatores internos, como a consciência sobre necessidades pessoais e profissionais de aprendizagem, pelos próprios profissionais, determinam a necessidade de educação continuada.

Já no final da década de setenta, a Organização das Nações Unidas para a Educação e a Ciência (UNESCO) priorizou, entre seus objetivos para os próximos anos, a idéia de educação permanente, definida como um processo que deve continuar por toda a vida adulta ${ }^{(5)}$.

Dentre as várias definições existentes, a educação permanente vem sendo considerada como um processo amplo que envolve aspectos do desenvolvimento integral do ser humano, não se limitando a treinamentos técnicos formais.

Desse modo, "a educação continuada é um processo prolongado que vai além dos limites dos sistemas educacionais, fazendo-se presente por toda a vida dos indivíduos, situados em uma sociedade em contínuas transformações; esta sociedade produz novas tecnologias, novos conhecimentos, mobilizando as possibilidades e os saberes dos profissionais, colocando a necessidade de continuidade na formação dos mesmos"(6).

Os serviços de educação permanente nas instituições de saúde oferecem, em geral, oportunidades de aprendizado na forma de educação em serviço, mas quem vai aprender é a pessoa, conforme seu grau de necessidade e motivação.

A educação continuada em ambiente hospitalar é geralmente utilizada com o objetivo de racionalizar recursos 
por meio da padronização de procedimentos e do melhor desempenho dos profissionais. Essa denominação seria mais adequada como desenvolvimento de pessoal, cujos objetivos são, como vimos, dirigidos para as finalidades da empresa.

As atividades educativas, nos serviços de saúde em geral, caracterizam-se pela fragilidade de inserção institucional e modismos pedagógicos, dependentes de dirigentes e normas institucionais muitas vezes acríticas. Para reverter essa situação, é necessário chegar à essência da questão, abstraindo a realidade e compreendendo os fenômenos na sua realidade concreta, estabelecendo correlações entre o processo produtivo e o educativo.

O trabalho na área hospitalar está organizado de maneira hierárquica, com verticalidade das relações de poder, que se repetem no âmbito das ações desenvolvidas, incluindo o setor de limpeza. Tal fato não favorece o diálogo, fragiliza as ações e com isso dificulta a realização de um trabalho de qualidade tanto por parte dos trabalhadores, que não conseguem dar sentido ao seu trabalho, quanto dos enfermeiros, que vêem sua função fragmentada, não exercendo integralmente sua atividade profissional.

O aprendizado, entendido como um processo ativo, contínuo e dependente de motivação, divide a responsabilidade da qualidade dos resultados obtidos nos programas de educação continuada entre seus organizadores e os participantes.

O enfermeiro educador pode promover um clima apropriado para facilitar o processo de aprendizado dos adultos, assegurando que os alunos estejam ativamente envolvidos nas discussões sobre a determinação das necessidades e dos resultados.

Os programas educativos devem ser compatíveis com os objetivos e prioridades da instituição, sendo sua eficiência avaliada por meio da observação da prática, já que é o olhar sobre as atividades cotidianas que permite ao educador identificar novas necessidades.

Compete ao enfermeiro propiciar suporte organizacional e administrativo para atingir os objetivos estabelecidos, assegurar que a estrutura proverá e facilitará experiências de aprendizado para os trabalhadores, permitindo que, no momento dispensado para a realização das atividades, eles estejam concentrados nela. CabeIhe, também, o planejamento das atividades, levando em consideração as necessidades desses trabalhadores, do serviço e a implantação do processo educativo.

\section{OBJETIVOS}

Contextualizar e analisar as atividades de educação continuada desenvolvidas junto aos trabalhadores terceirizados que atuam no setor de limpeza de um hospital universitário, em Campinas.

Avaliar o conhecimento dos trabalhadores em relação à contaminação do ambiente em que trabalham e à manutenção de sua saúde.

\section{METODOLOGIA}

Os sujeitos desta pesquisa foram os trabalhadores terceirizados do setor de limpeza, de um hospital universitário público do interior do Estado de São Paulo e os profissionais responsáveis pela sua educação continuada. Foi utilizada uma abordagem qualitativa, com a utilização de entrevista semi-estruturada e a observação do trabalho realizado.

A iniciativa desta pesquisa deu-se a partir da possibilidade concreta de intervenção sobre a educação continuada desses trabalhadores, possibilitando maior conscientização em relação ao processo saúde-doença. Nesse sentido, este estudo tem a intenção de dar continuidade à pesquisa "Gênero \& Reestruturação Produtiva: Terceirização e Impactos sobre a Saúde"(4), financiada pelo Programa Institucional de Bolsas de Iniciação Científica do Conselho Nacional de Pesquisa (PIBIC/CNPq), que objetivou traçar o perfil dos trabalhadores terceirizados que trabalham no setor de Serviços Gerais.

Foi acompanhado, também, o planejamento das enfermeiras para os encontros, como uma estratégia que possibilitou a aproximação junto aos trabalhadores, além de facilitar a contextualização do processo de educação continuada desenvolvido junto a eles.

O instrumento utilizado para a coleta de dados foi a entrevista semi-estruturada, junto a seis trabalhadores terceirizados do setor de limpeza, que participaram das atividades de educação continuada, de um total de 191, sendo garantida a representatividade da amostra por gênero, horário e local de trabalho e junto a duas enfermeiras responsáveis pela educação continuada desses trabalhadores, totalizando oito entrevistas que foram gravadas e transcritas.

Não houve recusa por parte dos trabalhadores em 
participar da pesquisa. As entrevistas foram realizadas nos meses de novembro e dezembro de 2000. Os dados foram submetidos a procedimentos analíticos por meio da sua codificação, descrição e interpretação.

Além das entrevistas, foram realizados quatro períodos de observação das atividades desenvolvidas junto aos trabalhadores, visando analisar a adequação da metodologia utilizada e dos conteúdos abordados nos encontros, sendo utilizado um diário de campo para tal fim.

Visto que a observação como um método de coleta de dados depende, em grande parte, do significado que o investigador lhe atribui no processo de investigação, deve ser ressaltado que o objetivo em relação aos períodos de observação foi registrar o comportamento dos enfermeiros e dos trabalhadores nos encontros.

Em relação aos aspectos éticos, o projeto de pesquisa foi aprovado pelo Comitê de Ética da Faculdade de Ciências Médicas da Universidade Estadual de Campinas (UNICAMP). Foi utilizado o termo de consentimento livre e esclarecido.

Os encontros

As enfermeiras responsáveis pelo setor de limpeza e pela educação continuada atribuem a construção do plano para os encontros uma função de orientação, de previsão das atividades a serem realizadas em sala, de modo que o tempo possa ser utilizado da melhor maneira possível para que os alunos aprendam. Contudo, a flexibilidade desse plano permite que assuntos de interesse dos trabalhadores possam ser trabalhados em algumas situações.

Durante o planejamento, as enfermeiras situaram, em primeiro lugar, os conteúdos, não dimensionando a metodologia que seria utilizada nos encontros. Dessa forma, o plano desenvolvido teve como referência os conteúdos a serem desenvolvidos e o conhecimento que os trabalhadores deveriam ter sobre o assunto.

\section{ENTREVISTA COM AS RESPONSÁVEIS PELO SETOR}

A educação continuada é realizada junto aos trabalhadores terceirizados do setor de Serviços Gerais por duas enfermeiras, contratadas pela empresa prestadora de serviços, que tinham um segundo emprego, como funcionárias do hospital, que não referiram outras experiências formais com o processo educativo. A idade média foi de 37 anos, o tempo de formada variou entre quatro e 14 anos e ambas são mulheres.

É importante destacar que as enfermeiras atuavam como representantes da empresa prestadora de serviços no hospital, tendo como responsabilidade principal manter o elo entre essa empresa, os demais funcionários e o contratante/cliente. Nesse sentido, exercem um duplo papel: de cobrança em relação aos trabalhadores e de subordinação em relação à empresa. A assimilação, ou não, desse papel denota uma postura diferenciada das enfermeiras, perpassada pela ideologia dominante que pode interferir no planejamento e implementação da educação continuada desenvolvida por elas.

A organização do trabalho e as relações de poder contextualizam a ideologia e a intencionalidade presente no conteúdo das entrevistas analisadas.

Quando questionadas sobre os conhecimentos necessários para a realização da limpeza de um hospital, as enfermeiras descreveram a necessidade de conhecimento das normas e rotinas da empresa:

Bom, eu considero assim..., no caso nosso, no meu caso que é uma prestadora e não um serviço próprio, eu considero que um funcionário saiba, é ... entenda das normas da empresa, da empresa prestadora, pra que, sabendo essas normas tem como ele nortear melhor o trabalho dele (Enfermeira 1).

Um outro dado que aparece em relação ao conhecimento necessário para a realização da limpeza hospitalar são os aspectos relacionados às técnicas de limpeza e aos produtos utilizados.

Então eu considero que um funcionário pra limpeza ele tem que saber técnica ele tem que entender de técnica, ele tem de entender alguma coisa do produto, também. É então é uma das grandes necessidades hoje. Produto que ele vai usar na limpeza, porque não é ele chegar lá e jogar este produto e fazer espuma é de limpar, não! Ele tem de entender de produto também (Enfermeira 1).

A enfermeira relatou, também, a importância da escolaridade para a assimilação e mudança de posicionamento dos trabalhadores em relação aos conhecimentos necessários.

Os outros são complementos que você ganha, que você adquire, que você treina, que você molda, mas estes pontos de saber ler, saber escrever são fundamentais (Enfermeira1).

Outro aspecto levantado em relação aos conhecimentos necessários para a realização da limpeza de um hospital diz respeito a questões de relacionamento e a características pessoais dos trabalhadores. 
Tem de ser uma pessoa tranqüila, tem de saber trabalhar em grupo, porque, não, não é um trabalho isolado, é um trabalho muito em grupo (Enfermeira1).

O conhecimento aparece nas falas como sendo um facilitador do processo de trabalho. Acho que no momento que eles puderem ter conhecimento eles vão conseguir fazer uma limpeza boa, né? (Enfermeira 2).

A segunda pergunta questionava a maneira como esses enfermeiros procuravam trabalhar esses conhecimentos junto aos trabalhadores.

O conteúdo das entrevistas com as enfermeiras não aborda a questão ideológica, restringindo-se, em grande parte, a explicar como é realizada a educação continuada dos trabalhadores.

Todo profissional, já na entrada, na admissão dele, ele tem um treinamento admissional, que é onde você passa as normas da empresa, como vai ser, o que a gente espera dele. E os demais são os treinamentos feitos anuais, que você faz, tem um cronograma que a gente pede anualmente, é feito em toda a empresa, em todo local que ela presta serviço, ela tem um cronograma anual. Por exemplo, agora em novembro em todo local onde a empresa presta serviço está sendo feito um treinamento, ou alguém começou, ou está começando, ou vai começar (Enfermeira 1).

\section{PERFILDOS TRABALHADORES ENTREVISTADOS}

A partir da pesquisa "Gênero \& reestruturação produtiva: terceirização e impactos sobre a saúde"(4), podese observar a baixa qualificação profissional desses trabalhadores, visto que "[...] $8 \%$ da população estudada não freqüentou a escola e $64 \%$ tinha escolaridade entre a $1^{\underline{a}}$ e a $7^{\underline{a}}$ série do ensino fundamental. A maioria destes trabalhadores era do sexo feminino (74\%), sendo que sua inserção no mercado de trabalho ocorreu em idade precoce, para ajudar a família no orçamento doméstico. Foi percebido também um elevado índice de rotatividade no serviço, cerca de $44 \%$ destes trabalhadores são funcionários da empresa há menos de um ano".

O nível de escolaridade dos trabalhadores que aceitaram participar da pesquisa é diferenciado em relação ao contingente real descrito acima.

Tabela 1 - Distribuição dos trabalhadores do serviço terceirizado de limpeza de um hospital universitário segundo características demográficas e outras de interesse para o estudo. Campinas, 2000

\begin{tabular}{|c|c|c|c|c|c|c|c|c|}
\hline & Sexo & $\begin{array}{l}\text { Idade } \\
\text { (anos) }\end{array}$ & $\begin{array}{c}\text { Estado } \\
\text { civil }\end{array}$ & Função & Escolaridade & $\begin{array}{c}\text { Ano } \\
\text { conclusão }\end{array}$ & Local trabalho & $\begin{array}{l}\text { Horário } \\
\text { trabalho }\end{array}$ \\
\hline $\bar{E} 1$ & Fem & 34 & Solteira & Servente & $\begin{array}{c}3^{a} \text { série ensino } \\
\text { fundam ental }\end{array}$ & 1976 & $\begin{array}{c}\text { Área } \\
\text { assistencial/ } \\
\text { administrativa }\end{array}$ & $6: 00-14: 00 \mathrm{~h}$ \\
\hline E 2 & Fem & 42 & Viúva & Servente & $\begin{array}{l}5^{\text {a }} \text { série ensino } \\
\text { fundam ental }\end{array}$ & 1976 & Área Hospitalar & $14: 00-22: 00 \mathrm{~h}$ \\
\hline E 3 & Fem & 27 & Viúva & Servente & $\begin{array}{l}5^{\text {a }} \text { série ensino } \\
\text { fundam ental }\end{array}$ & 1999 & $\begin{array}{c}\text { Laboratório no } \\
\text { Hospital }\end{array}$ & $14: 00-22: 00 \mathrm{~h}$ \\
\hline E 4 & Fem & 38 & Casada & Servente & $\begin{array}{c}5^{\mathrm{a}} \text { série ensino } \\
\text { fundam ental }\end{array}$ & 1973 & Área Hospitalar & $14: 00-22: 00 \mathrm{~h}$ \\
\hline E 5 & Fem & 31 & Casada & Servente & $\begin{array}{c}\text { Ensino médio } \\
\text { completo }\end{array}$ & 1996 & Área Hospitalar & $14: 00-22: 00 \mathrm{~h}$ \\
\hline E 6 & Masc & 41 & Solteiro & Servente & $\begin{array}{l}7^{\text {a }} \text { série ensino } \\
\text { fundamental }\end{array}$ & Não lembra & $\begin{array}{c}\text { Coleta de lixo } \\
\text { Hospitalar }\end{array}$ & $6: 00-12: 00 h$ \\
\hline
\end{tabular}

E1 a E6 - Entrevistas com trabalhadores do setor de limpeza

A análise das entrevistas dos trabalhadores deuse por meio dos seguintes temas:

- O que eles esperavam do treinamento.

- As dificuldades encontradas no trabalho dentro do hospital.

- Se acreditavam que o trabalho afetaria sua saúde e, em caso afirmativo, de que forma.

- O que achavam necessário saber para trabalhar no setor de limpeza de um hospital.

A educação continuada se faz muito importante para esses trabalhadores, uma vez que, para muitos, é a primeira vez que realizam atividade de limpeza em hospital. Além disso, aprendem não só como fazer uma limpeza hospitalar, mas também aspectos referentes à sua proteção, por meio do uso de equipamentos de proteção individual.

O que esperam do "treinamento"

Em geral, foi referido pelos trabalhadores que esperam obter conhecimentos referentes ao trabalho que irão executar, tendo em vista sua ausência/pequena experiência.

Este treinamento pra mim é muito bom. Ótimo, que a gente aprende trabalhar melhor, e se comportar melhor e tudo mais. Ensina muita gente a trabalhar também em área hospitalar, que tem muita 
gente nova que num sabe, né? (E1).

Eu espero que a gente tenha mais qualidade de trabalho.

Que a gente trabalhe com mais segurança, mais informações sobre o setor, sobre estar manuseando os produtos direitinho (E3).

Bom, a gente espera esclarecimento do que a gente vai precisar no dia a dia do nosso trabalho. Quando houve a greve as pessoas saíram e a gente entrou pra fazer uma limpeza. Então a gente passou por um treinamento rápido, mas em seguida elas(enfermeiras) já fizeram um treinamento pra que a gente fizesse um serviço perfeito. O treinamento foi importante pra gente, né? Porque a gente veio assim sem experiência. Que nem eu, não tinha experiência e ela passou os cuidados pra gente, então foi muito útil. Valeu porque a gente não tinha noção. Muitos não tinham a noção do que era uma limpeza hospitalar (E5).

As dificuldades encontradas

Em relação às dificuldades que esperam encontrar no trabalho dentro do hospital, as respostas foram diversificadas, sendo citados desde problemas com a enfermeira, até os relacionados com a própria saúde, sendo incluídos aí os acidentes de trabalho.

Acidente. Ah, é uma agulha pelo chão. Fora da caixinha, sabe? Eu mesma já fui vítima de uma, que eu já furei o dedo, entendeu? $O$ que eu acho que é mais difícil é isso, a contaminação, né? Se agente não tiver cuidado, né? (E4).

Dificuldade? Foi tudo, né, meu? Tudo. Tive muita dificuldade. É limpar parede. Esse negócio de limpar parede, limpar aí. Hospital tem uma coisa que não tem nada a ver, viu? Só isso aí (E6).

O trabalho afetando sua saúde

Os trabalhadores sabem que esse tipo de trabalho afeta sua saúde, porém eles não têm uma compreensão do todo; alguns citaram apenas os acidentes de trabalho e a contaminação, e nem todos citaram os dois problemas.

Afeta. Se você não saber trabalhar, se você não tiver cuidado, se você não usar luva direitinho, os preparativos direito. Mesmo você usando os preparativos você ta arriscado a uma contaminação e sem você usar é pior ainda, né? (E1).

Ah sim, se não tiver cuidado afeta sim. Assim, é que nem eu mesmo já me machuquei, já sofri um acidente, né? Quer dizer, é arriscado me contaminar, né? Através dessa picada da agulha, entendeu? (E4).

Bom, aí vai depender dos cuidados que a gente possa ter. Por exemplo, se eu sei que o ambiente ta contaminado o que vou fazer? Vou usar avental, máscara, que mais, luva. Deixa eu ver?
Cuidado, principalmente o cuidado. Cuidado, o mais importante é ter cuidado, porque aqui já aconteceu vários acidentes... (E5).

O que é necessário saber para trabalhar no setor

Em relação ao que acham necessário saber para trabalhar no setor de limpeza de um hospital, os trabalhadores disseram já saber tudo, principalmente sobre o uso de equipamentos de proteção individual.

Ah! O que eu gostaria de saber é isso que eu já estou sabendo, que é esse treinamento novo, né? É como usar luvas e isso, e aquilo e tudo isso. Coisas que eu não sabia quando eu entrei ... Hoje não, hoje você manda eu limpar qualquer setor e eu sei como mexer. É usar luva, é máscara, é bota, é avental, é tudo isso de contaminação. Tudo isso eu sei, mas quando eu entrei eu não sabia (E1).

O que é necessário? Bom, tudo né? (...) Assim porque como eu te falei, a gente aqui chegou assim, sem saber nada, a gente não sabia nada, não tinha experiência do que era uma limpeza hospitalar, mas é assim de imediato você falando alguma coisa a gente não tem assim tanta dificuldade. Porque elas (enfermeiras) vinham acompanhando a gente. Elas ficaram com a gente até a gente aprender mais um pouco pra ficar sozinho. Não senti então um monte de dificuldades não (E5).

É feita referência, também, ao fato de não ter experiência anterior na área hospitalar:

É o meu primeiro emprego na limpeza hospitalar, né? Então não sei o que te dizer, não sei te responder. Elas vieram explicando: Não é assim. É assim. Faz de novo. Procure usar tal equipamento porque precisa (E5).

\section{DISCUSSÃO DOS DADOS}

A educação é um fenômeno próprio do ser humano que, por meio de ações intencionais, transforma a natureza para sua conveniência. Isso implica afirmar que a educação é uma exigência do processo de trabalho, sendo ela própria, em sua natureza, um processo de trabalho não material $^{(7)}$

$\mathrm{Na}$ análise dos dados foi possível observar que as enfermeiras responsáveis pela educação continuada entendem a baixa escolaridade dos trabalhadores como um fator que dificulta o processo de aprendizagem desses profissionais.

Sobre o conhecimento que elas consideram necessário para a realização da limpeza de um hospital, podemos citar os seguintes: relativo às normas e rotinas 
da empresa, às técnicas e aos produtos utilizados; assim como os aspectos referentes ao relacionamento e às características pessoais dos trabalhadores. Ele aparece nas falas como sendo um facilitador do processo de trabalho.

Cabe-nos indagar, como educadores, que conhecimento estamos produzindo e socializando e para quê, com que objetivos; nessa perspectiva, portanto, a dimensão ética deve perpassar todas as relações do processo educativo.

Ainda que a educação continuada tenha a tendência de se restringir ao aspecto da qualidade formal e, algumas vezes, a meros "treinamentos", é possível propiciar condições para a construção da consciência crítica, o que possibilita perspectivas mais favoráveis para a competência política. Freqüentemente, a qualidade do processo de educação continuada defronta-se com essa contradição, porque profissionais com maior empenho e atualização são mais exigentes quanto às suas expectativas políticas, sociais e no trabalho.

A educação continuada realizada pelas enfermeiras tem por finalidade que o funcionário conheça as normas da empresa que o contratou e que presta serviços ao hospital, tendo como referência o desempenho das funções, tendo como objetivo primordial a produtividade.

Durante a atividade em sala de aula, foram abordados os seguintes temas: uso dos produtos, como evitar contaminações por meio do uso de equipamentos de proteção individual e a conservação desses equipamentos. Porém, não foram abordados assuntos como: postura corporal correta na realização das atividades de trabalho, transferência de equipamentos correta. A empresa não oferece equipamentos adequados, como vassouras com cabo adaptável e baldes na altura ideal. Não há informação aos trabalhadores sobre possíveis doenças como DORT (Doenças Osteomusculares Relacionadas ao Trabalho) / LER (Lesões por Esforços Repetitivos), que podem estar relacionadas às "características do posto, dos instrumentos e do ambiente de trabalho"(8).

Nas atividades, é feita referência aos acidentes de trabalho com materiais perfurocortantes e à contaminação no ambiente de trabalho, que, em geral, podem acarretar custos para a empresa. Os acidentes de trabalho são, muitas vezes referidos como tendo ocorrido por falta de atenção dos trabalhadores e não necessariamente pela sua falta de informação e/ou dificuldade em assimilar novas informações. Isso é relatado por um trabalhador entrevistado:

(...) Cuidado, principalmente o cuidado. Cuidado, o mais importante é ter cuidado, porque aqui, já aconteceram vários acidentes. Mas, ela (enfermeira) vem bater na mesma tecla. Por que tá havendo acidentes com freqüência? Então, quando a gente vai conversar nas reuniões que tem, a gente vai conversar e vai percebendo aquela pessoa assim, que vai se desligando do serviço, conversando com o colega e de repente aconteceu um acidente (E5).

As enfermeiras, ao realizarem as atividades de educação continuada junto aos trabalhadores, utilizaram a linguagem e os termos presentes no cotidiano deles, possibilitando a aproximação entre ambos. Embora elas tivessem autonomia em relação à educação continuada dos funcionários da limpeza, a empresa exigia que fossem desenvolvidas atividades em sala de aula. Uma das enfermeiras fazia a educação continuada também no cotidiano dos funcionários, observando o trabalho desenvolvido e corrigindo, na hora, possíveis erros que eles poderiam estar cometendo.

Nesse sentido, temos que o processo de reestruturação produtiva no Brasil repete outras experiências do mundo industrializado, trazendo um elevado grau de insegurança para os trabalhadores, fazendo com que muitos deles, sentindo-se subordinados à empresa, devido aos elevados índices de desemprego, neguem-se a participar de pesquisas como estas. Foi observado, na coleta de dados, que as pessoas com maior nível de escolaridade e as com maior tempo de serviço foram as que se dispuseram a participar, assim o perfil dos entrevistados é um pouco diferente da maioria dos funcionários da empresa.

"Em relação ao novo aspecto do processo, que é a transferência da produção para terceiras, a questão dos direitos e das condições de trabalho permanece, porém se acresce a isso a questão dos efeitos sobre o nível de emprego, salários, qualificação profissional, organização sindical, como conseqüência, sobre a saúde no trabalho"(1).

\section{CONSIDERAÇÕES FINAIS}

Percorrendo os caminhos que foram se delineando neste estudo, retomaremos alguns pontos que nos parecem relevantes e que possibilitam explicitar, de forma 
direta e indireta, as atividades de educação continuada que ocorrem junto aos trabalhadores terceirizados do Setor de Serviços Gerais de um Hospital Universitário.

Partimos do pressuposto de que essa situação ocorre em meio a um contexto histórico e que sua compreensão e apreensão vão se dando por meio de sucessivas aproximações, num processo dinâmico e contínuo de ampliação e superação de verdades parciais por meio de rupturas, descontinuidade e contradições que vão se dando nos planos econômicos, políticos, sociais e ideológicos. Olhar para essa situação permite a reflexão acerca do processo de planejamento e implementação das atividades de educação continuada, visto que essas atividades são permeadas de intencionalidade explícita ou não.

A análise advinda desse percurso possibilitou destacar alguns fatos que nos pareceram significativos, inter-relacionados, possibilitando uma aproximação e compreensão do tema em estudo.

O ensino é uma tarefa profissional, que exige um corpo de conhecimentos e saberes especializados e uma atuação racional e individual, tornando-se necessário aplicar técnicas pedagógicas adaptadas à situação concreta dos alunos e da turma, devendo ser pensado como um caminho de mão dupla.

Existe uma ideologia que perpassa o processo educativo, que pode ser utilizada como um espaço prescritivo, de dominação ou de libertação/emancipação dos indivíduos. No espaço da dominação, o interesse é o de formar sujeitos dependentes, alienados, acomodados às informações recebidas, sem criatividade e capacidade

\section{REFERÊNCAIS BIBLIOGRÁFICAS}

1. Repullo R. Os sindicatos, a terceirização e a saúde dos trabalhadores. Rev Bras Saúde Ocup 1997 set.; 23(85/86):7982.

2. Ramalho JR. Precarização do trabalho e impasses da organização coletiva no Brasil. In: Antunes R, organizador. Neoliberalismo, trabalho e sindicatos. Reestruturação produtiva no Brasil e na Inglaterra. Campinas (SP): Boitempo; 1999. p. 85-113.

3. Nascimento RH, Cocco MIM, Lopes MHBM. Desenvolvimento da especialidade saúde e trabalho, no departamento de enfermagem do hospital virtual brasileiro. Rev Latino-am Enfermagem 2003 mar/abr; 11(2):237-9.

4. Chillida MSP, Cocco MIM. Gênero \& reestruturação produtiva: terceirização e impactos sobre a saúde. Relatório Final de Pesquisa PIBIC/CNPq. Campinas (SP): Universidade Estadual de Campinas; 2000. de reflexão sobre a realidade na qual vivem ou sobre a qual irão atuar. No espaço que denominamos libertador, entendemos a formação de cidadãos, profissionais críticos, independentes, capazes de refletir e intervir sobre sua realidade educacional, social, política, econômica, cultural e profissional.

"No processo pedagógico que objetiva a construção do saber presencia-se o estímulo à reflexão, à capacidade de observação, de análise, de síntese, de crítica, à autonomia de pensar, tentando ampliar os horizontes do sujeito, tornando-o agente ativo que busca interagir com a realidade no qual está inserido; a educação assume uma função mediadora de uma prática social mais global e, a nosso ver, a metodologia de formação necessária é aquela capaz de fazer o aluno compreender criticamente, de maneira contextualizada a prática que exercerá profissionalmente, estabelecendo uma interação constante entre a teoria e prática" ${ }^{\prime(5)}$.

As respostas dos trabalhadores são breves e "empobrecidas". Talvez isso possa ser atribuído ao trabalho alienado realizado, no qual o trabalhador não tem a "noção" do produto final de seu trabalho, e, também, como às condições de vida/ baixa escolaridade e/ou medo de perder o emprego.

Como a terceirização dos serviços de limpeza na área de saúde tem-se ampliado nos últimos anos, é fundamental que esses trabalhadores, em geral com baixa qualificação profissional, possam exercer seu trabalho com conhecimento e tenham condições adequadas para executá-lo, tendo em vista os riscos ocupacionais a que estão expostos.

5. Organização das Nações Unidas para a Educação e a Ciência - Unesco. Nova estratégia para educação. Rev Bras Est Pedag 1973 jan/mar; 59(129):157-72.

6. Bagnato MHS. Educação continuada na área da saúde: uma aproximação crítica. In: Bagnato MHS, Cocco MIM, Sordi MRL, organizadoras. Educação, saúde e trabalho: antigos problemas, novos contextos, outros olhares. Campinas (SP): Alínea; 1999. p. 71-98.

7. Saviani D. Pedagogia histórico-critica: primeiras aproximações. 4. ed. Campinas (SP): Autores Associados; 1994.

8. Assunção AA, Rocha LE. Agora ... até namorar fica difícil: uma história de lesões por esforços repetitivos. In: Rocha LE, Rigotto RM, Buschinelli JTP, organizadores. Isto é trabalho de gente? Vida, doença e trabalho no Brasil. Petrópolis (RJ): Vozes; 1994. p. 461-93. 